\title{
Electrocardiographic diagnosis of pacemaker catheter displacement
}

\author{
Thomas A. Preston, M.D., F.A.C.C. \\ Ann Arbor, Mich.
}

\begin{abstract}
$\mathrm{C}$ atheter displacement is an infrequent but bothersome cause of failure of implanted pacemaker systems. The prevalence of catheter displacement is $6^{1}$ to 45 per cent ${ }^{2}$ of all permanent transvenous catheter implantations. Displacement can occur at any time, but is most common within the first month, and has occurred as many as 24 months after implantation. ${ }^{1}$ Marked catheter displacement usually results in intermittent or total failure of pacing, with return of the symptoms experienced before artificial pacing. Occasionally, catheter movement does not result in loss of pacing, and there may be no sign or symptom to indicate the problem.

This is a report of the use of the electrocardiogram (ECG) pacemaker stimulus artifact to detect catheter movement. Plotting of the frontal and horizontal plane vector of the stimulus artifact, derived from a standard twelve lead ECG, usually gives enough information to detect gross catheter tip movement.
\end{abstract}

\section{Methods}

One hundred forty-six permanent pacing catheters were implanted between January, 1968, and January, 1972. During this period 14 patients had 16 episodes requiring repositioning of catheter electrodes. In seven cases both ECG's and $\mathrm{x}$-rays were not taken or kept both before and after repositioning, and therefore it was not possible to include these cases in this analysis. In six patients, the tip of the catheter electrode remained in the right ventricle but failed to stimulate the ventricle regularly; in two patients the catheter tip moved to the right atrium; in one patient the catheter tip perforated the right ventricle without loss of ventricular pacing.

ECG's and $\mathrm{x}$-rays taken before and after catheter displacement were analyzed (see Table I). The frontal plane vector of the pacemaker stimulus artifact was plotted from the extremity leads as described by Green and colleagues. ${ }^{3}$ The horizontal plane vector was plotted from the precordial leads. In the absence of orthogonal leads, this measurement is not precise but is accurate enough to detect changes of 30 degrees or greater. In all cases, the catheter electrode was bipolar. See Table I for the manufacturer and model number.

\section{Results}

In all nine cases there was $x$-ray evidence of movement of the pacemaker catheter, although in cases $2,4,6,8$, and 9 the movement was minimal and did not result in a marked change in the direction of the stimulus vector. In the remaining four cases there was a large change in the direction of

From the University of Michigan Medical Center, Ann Arbor, Mich.

Received for publication May 1, 1972.

Reprint requests to: Thomas A. Preston, M.D., Veterans Administration Hospital, Ann Arbor, Mich, 48105. 


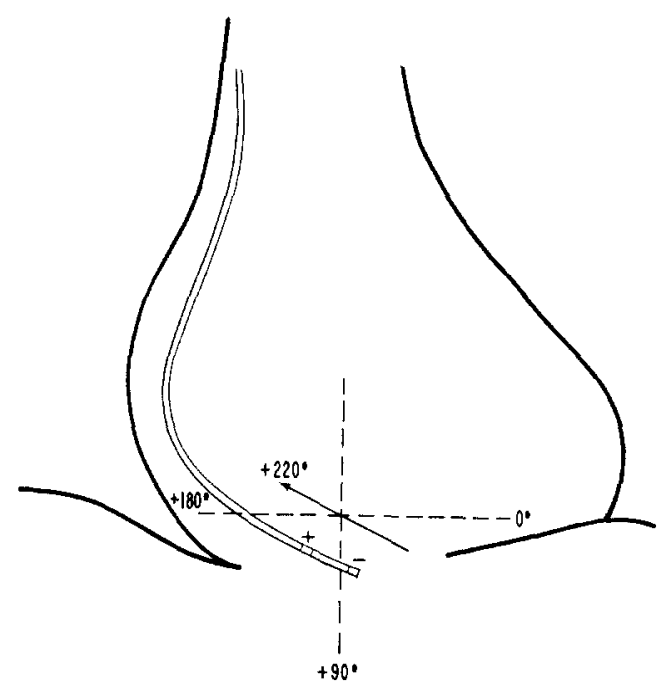

Fig. 1A. Diagram of the orientation of the catheter at about +220 degrees in the frontal plane.

the pacemaker stimulus vector which correlated with change of position of the catheter tip on $\mathrm{x}$-ray. An example is shown in Figs. 1 to 4 . Marked catheter tip movement was always associated with a change in the frontal or horizontal plane vector of greater than 90 degrees. We also had three cases of electrode break which resulted in a change of the direction and amplitude of the stimulus vector as a result of the system operating in the unipolar mode. ${ }^{3}$ In these three cases, $\mathrm{x}$-rays showed no change in catheter position and the amplitude of the stimulus artifact increased greatly.

Catheter displacement was detected initially from the ECG in only three cases, although in other cases there was a significant stimulus vector change which was not appreciated.

\section{Discussion}

Many investigators have used analysis of the pacemaker stimulus artifact to detect or diagnose changes in pacemaker function..$^{1-6}$

Analysis has usually been of the stimulus artifact amplitude, duration, and configuration. Slight drift or change in the direction of the frontal plane vector is common in stable systems, especially with bipolar catheters. This drift, however, is never as much as 90 degrees, and with a bipolar
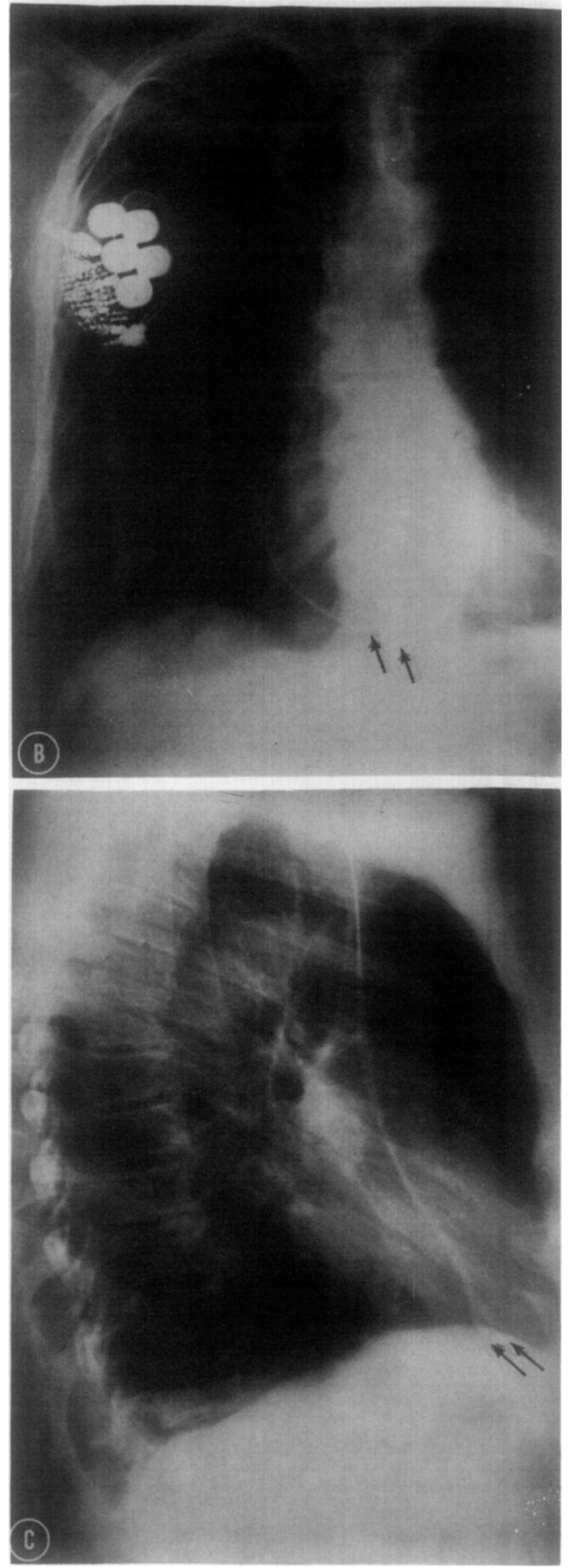

Fig. $1, B$ and $C$. Pulmonary artery and lateral chest $\mathrm{x}$-rays after implantation but prior to displacement. The arrows point to the bipolar electrodes. 


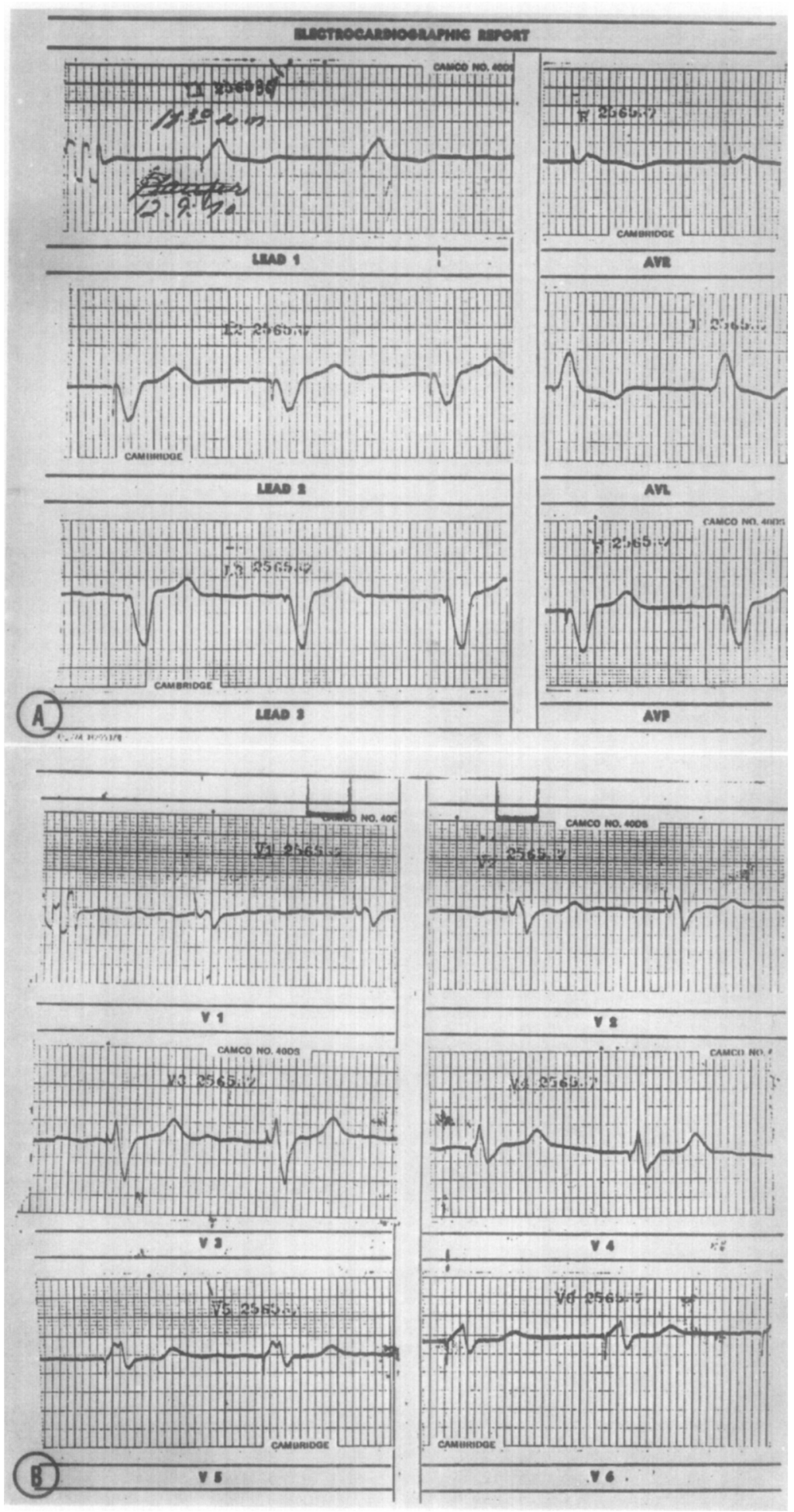

Fig. 2, $A$ and $B$. Electrocardiogram prior to catheter displacement. Stimulus artifact vector is +220 degrees in the frontal plane, and +190 degrees in the horizontal plane. 
Table I. ECG stimulus artifact vectors

\begin{tabular}{|c|c|c|c|c|c|c|c|}
\hline \multirow{3}{*}{ Patient } & \multirow{3}{*}{ Catheter } & \multicolumn{5}{|c|}{ Pacemaker stimulus artifact } & \multirow{3}{*}{$\begin{array}{l}\text { Catheter } \\
\text { position }\end{array}$} \\
\hline & & \multicolumn{2}{|c|}{ Before displacement } & \multicolumn{3}{|c|}{ After displacement } & \\
\hline & & $\begin{array}{c}\text { Frontal } \\
\text { vector }\end{array}$ & $\begin{array}{l}\text { Horizontal } \\
\text { vector }\end{array}$ & $\begin{array}{c}\text { Frontal } \\
\text { vector }\end{array}$ & $\begin{array}{l}\text { Horizontal } \\
\text { vector }\end{array}$ & $\begin{array}{c}\text { Time post } \\
\text { implant }\end{array}$ & \\
\hline K. S. & Medtronic 5818 & $+220^{\circ}$ & $+190^{\circ}$ & $+120^{\circ}$ & $+240^{\circ}$ & 12 months & $\begin{array}{l}\text { Catheter in } R V,{ }^{*} \text { point- } \\
\text { ing up, left, anterior }\end{array}$ \\
\hline N. C. & Medtronic 5818 & $+210^{\circ}$ & $+210^{\circ}$ & $+210^{\circ}$ & $+210^{\circ}$ & 2 months & $\begin{array}{l}\text { Catheter pulled back } \\
2 \mathrm{~cm} \text {. }\end{array}$ \\
\hline S. J. & GE A2070DA & $+210^{\circ}$ & $+220^{\circ}$ & $+120^{\circ}$ & $+120^{\circ}$ & 2 months & $\begin{array}{l}\text { Catheter in RV, point- } \\
\text { ing up, left, posterior }\end{array}$ \\
\hline S. J. & GE A2070DA & $+180^{\circ}$ & $+200^{\circ}$ & $+200^{\circ}$ & $+180^{\circ}$ & 2 months & $\begin{array}{l}\text { Catheter pulled back } \\
2 \mathrm{~cm} .\end{array}$ \\
\hline B. R. & Medtronic 5818 & $+270^{\circ}$ & $+270^{\circ}$ & $+20^{\circ}$ & $+70^{\circ}$ & 1 month & $\begin{array}{l}\text { Catheter in RA, point- } \\
\text { ing right and posterior }\end{array}$ \\
\hline H. M. & Medtronic 5818 & $+200^{\circ}$ & $+200^{\circ}$ & $+210^{\circ}$ & $+200^{\circ}$ & 7 months & $\begin{array}{l}\text { Catheter pulled back } \\
2 \mathrm{~cm} .\end{array}$ \\
\hline G. J. & Medtronic 5818 & $+210^{\circ}$ & $+210^{\circ}$ & $+80^{\circ}$ & $+40^{\circ}$ & 3 months & $\begin{array}{l}\text { Catheter in RA, point- } \\
\text { ing up and posterior }\end{array}$ \\
\hline W. J. & Medtronic 5818 & $+210^{\circ}$ & $+200^{\circ}$ & $+210^{\circ}$ & $+200^{\circ}$ & 1 week & $\begin{array}{l}\text { Catheter pulled back } \\
1 \mathrm{~cm} .\end{array}$ \\
\hline K. S. & Medtronic 5818 & $+220^{\circ}$ & $+200^{\circ}$ & $+220^{\circ}$ & $+200^{\circ}$ & 2 days & $\begin{array}{l}\text { Catheter perforated RV } \\
\text { without loss of pacing }\end{array}$ \\
\hline
\end{tabular}

*Abbreviations: $\mathrm{RV}=$ right ventricle; $\mathrm{RA}=$ right atrium.

system it can be induced by breathing or by a change in body position.

Noting a change in the direction of the frontal plane vector on a standard ECG led to the diagnosis of catheter displacement in three cases. Epicardial electrodes may be attached so as to produce almost any stimulus vector, and as epicardial leads do not migrate, any change in the stimulus vector indicates an electrode break. Alternatively, a normally positioned transvenous catheter bipolar electrode always gives a stimulus vector which points to about 210 degrees in the frontal plane (Fig. 1) and is directed slightly posteriorly in the horizontal plane. Thus all normally positioned bipolar catheter electrodes have a similar stimulus vector direction, and any marked change indicates a change in the catheter electrode position or integrity. This statement applies only to a bipolar catheter, however, as with a unipolar system the single intracardiac electrode may move a relatively great distance without producing a marked (90 degrees or more) change in the stimulus vector. When both electrodes are intracardiac a movement of the catheter tip results in a change in the direction of the stimulus vector unless the spatial orientation of the catheter tip does not change.

Green and co-workers ${ }^{3}$ have reported stimulus vector changes due to electrode breaks. In our experience electrode breaks have either resulted in disappearance of the stimulus artifact (open circuit), or a change to unipolar pacing due to a break in the insulation, resulting in no change in the stimulus vector direction but a large increase in the amplitude. In the latter case, the vector direction did not change because the indifferent electrode was in the right pectoral area. Thus the unipolar vector had the same general direction as the bipolar vector. Where the power unit was implanted on the left side, a break resulting in unipolar stimulation would also result in a change in the direction of the stimulus vector.

In five of our cases, the catheter movement was no more than $2 \mathrm{~cm}$. and the tip was still in the right ventricle, with no 

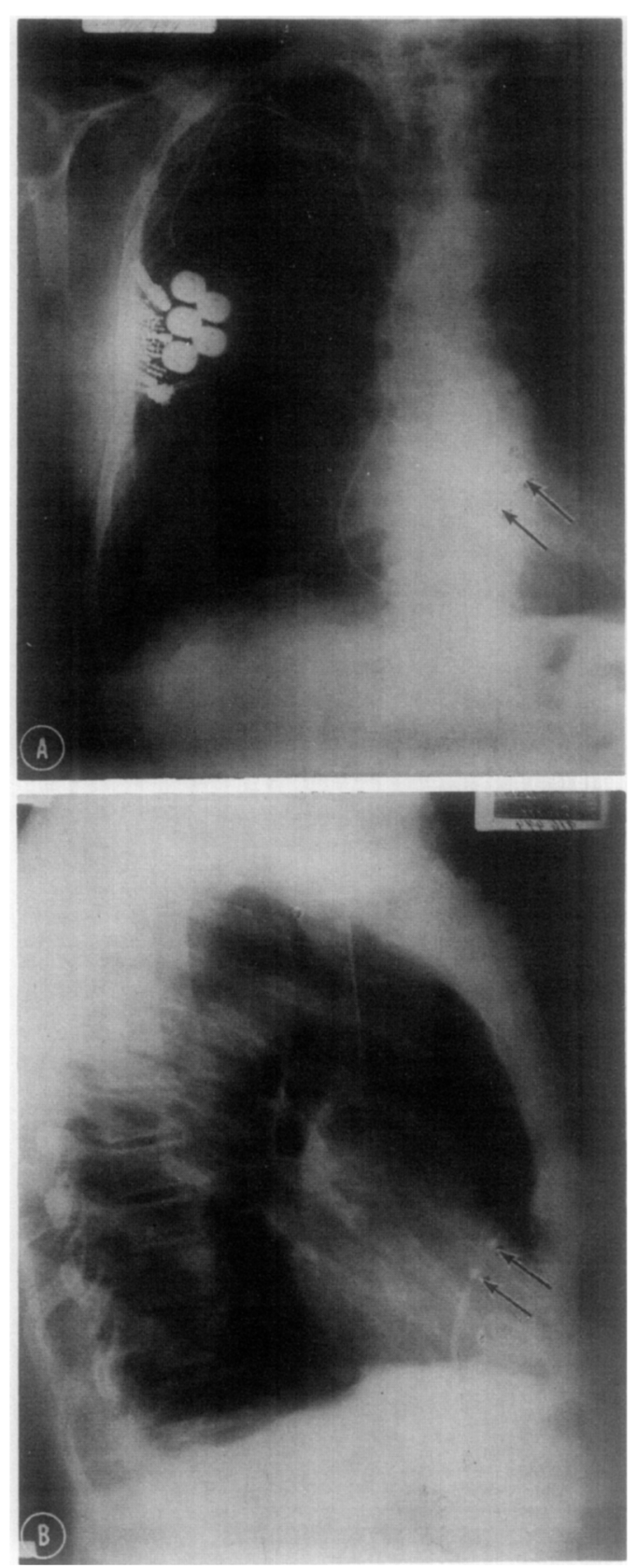

Fig. 3, $A$ and $B$. Chest x-ray after catheter displacement. Catheter tip now points up and to the right. Stimulus vector points from negative to positive electrode.

stimulus vector change. There was, however, loss of pacing, presumably due to the catheter moving to a position where the electrode made less contact with the endocardium, resulting in a higher excitation threshold. This is a situation analogous

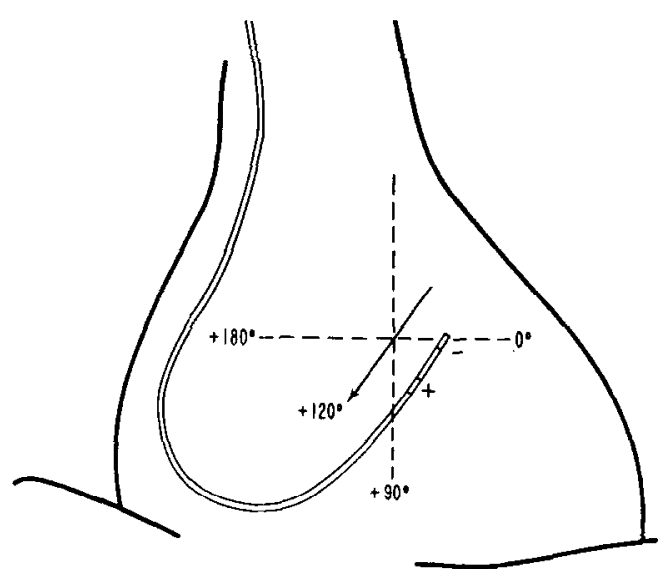

Fig. $3 C$. For legend see $3 A$ and $B$.

to pacemaker exit block ${ }^{7}$ in which the stimulus is insufficient for the threshold of that particular electrode system. Although long-term medical treatment to decrease the threshold might be effective in minor catheter displacements, repositioning of the catheter is a better solution to the problem.

It is possible that a catheter electrode might drastically change position but remain within the right ventricle with no loss of pacing and no other sign or symptom of the displacement. Thus there would be no reason to suspect a problem, but plotting the stimulus vector would show that the catheter was not in the normal position. This is a further reason for obtaining a routine ECG at every pacemaker patient visit.

It is easy to plot the pacemaker stimulus vector in one's mind by glancing at a standard twelve lead ECG. Detecting a vector direction which is not normal for a bipolar pacing catheter, or which is significantly changed from previous ECG's, is a quick and simple method of detecting possible catheter displacement.

\section{Summary}

Displacement of permanent pacemaker catheters occurs in about 10 per cent of primary implantations, and can be a cause of "pacemaker failure." If movement of the catheter tip is $2 \mathrm{~cm}$. or less there is usually no change of the stimulus artifact on the standard ECG, but marked changes in catheter position do result in changes of the amplitude and direction of the pacemaker stimulus artifact. Four episodes of 


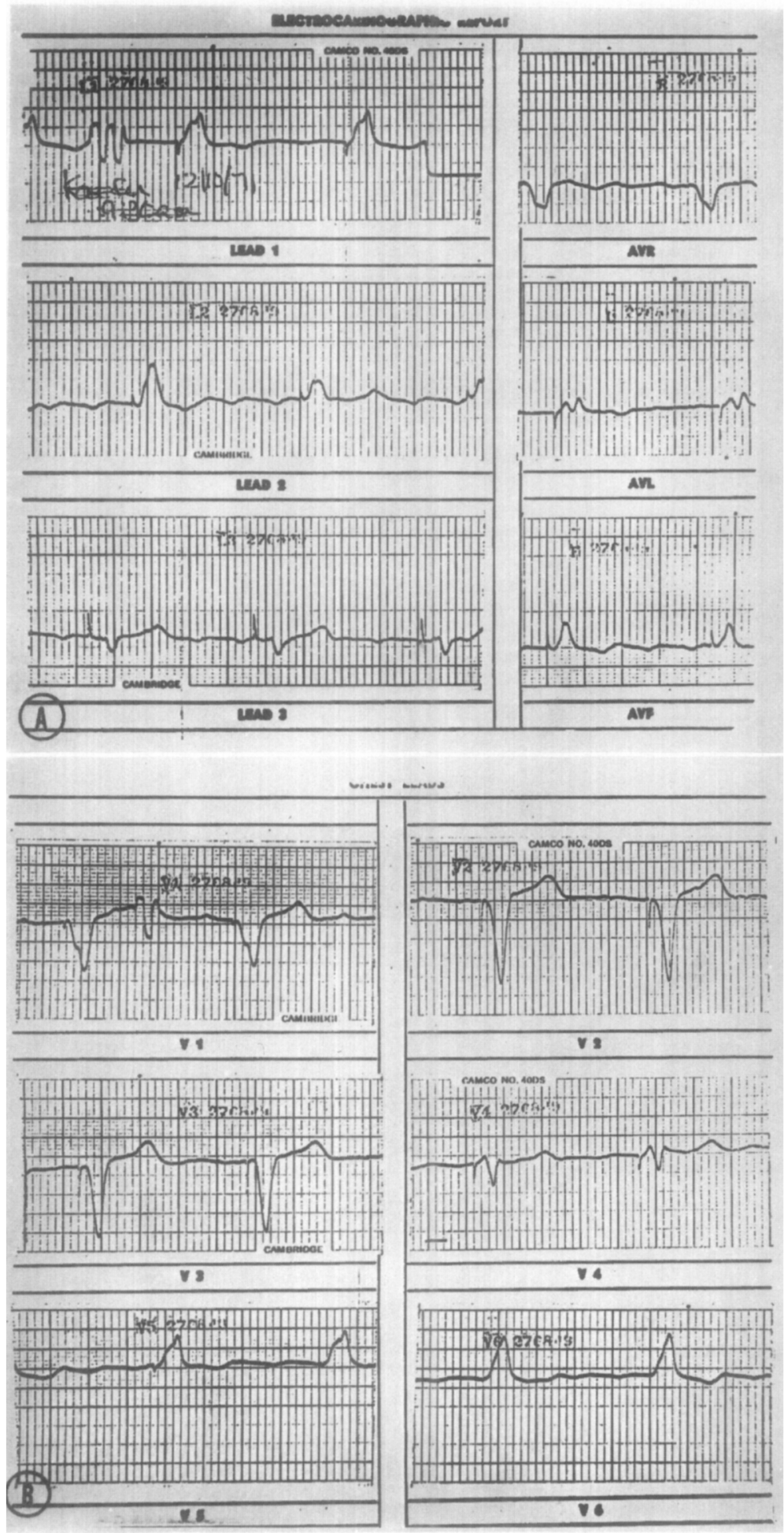

Fig. 4, $A$ and $B$. Electrocardiogram after displacement. Stimulus artifact vector is now +120 degrees in the frontal plane, and +240 degrees in the horizontal plane. 
catheter displacement resulted in changes of the stimulus artifact vector direction of greater than 90 degrees in either the frontal or horizontal planes. Rapid screening of the routine ECG is an effective means of detecting catheter displacement, with or without loss of pacing.

\section{REFERENCES}

1. Furman, S., and Escher, D. J.: Principles and techniques of cardiac pacing, New York, 1970, Harper \& Row, Publishers, p. 244.

2. Bluestone, R., Davies, G., Harris, A., Leatham, A., and Siddons, H.: Long-term endocardial pacing for heart block, Lancet 2:307, 1965.

3. Green, G. D., Forbes, W., Bain, W. H., and
Shaw, G. B.: Detecting break in insulation in negative pacemaker lead, $\mathrm{Br}$. Med. J. 4:645, 1968.

4. Knuckey, L., McDonald, R., and Sloman, G.: A method of testing implanted cardiac pacemakers, Br. Heart J. $27: 483,1965$.

5. Thalen, H. J., van den Berg, J. W., van der Heide, J. N., and Nieveen, J.: The artificial cardiac pacemaker, Charles C Thomas, Publisher, Springfield, and Royal VanGorcum, Assen, the Netherlands, 1969, p. 269.

6. Gordon, A. J.: Vector analysis of the stimulus artefact in patients with endocardial pacemakers, J. Electrocardiol. 4 (Suppl. 2):91, 1971.

7. Preston, T. A., Judge, R. D., Lucchesi, B. R., and Bowers, D. L.: Myocardial threshold in patients with artificial pacemakers, Am. J. Cardiol. 18:83, 1966. 